REGE

25,3

Received 4 June 2017

Revised 5 June 2017

Accepted 5 February 2018

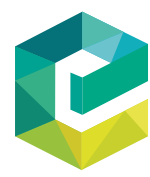

Revista de Gestão Vol. 25 No. 3,2018 pp. $258-273$ Emerald Publishing Limited 2177-8736 DOI 10.1108/REGE-05-2018-0074

\section{Main dimensions that impact knowledge management and university-business-government collaboration in the Brazilian scenario}

\author{
Suzana Xavier Ribeiro and Marcelo Seido Nagano \\ Engenharia de Produção, \\ Universidade de Sao Paulo Escola de Engenharia de Sao Carlos, \\ Sao Carlos, Brazil
}

\begin{abstract}
Purpose - The purpose of this paper is to investigate how certain characteristics of the university-industrygovernment collaboration facilitate knowledge creation and management, hence innovation focusing on particularities of the Brazilian scenario.

Design/methodology/approach - As a conceptual basis, there are correlations between theories of knowledge management and the Triple Helix, a model referenced to university-industry-government cooperation. The research was conducted through a multiple case study at two National Institutes of Science and Technology (INCTs in Portuguese).

Findings - The main results show the importance of participation in the INCT program, as it enables the creation of an organizational structure with the coordinator's leadership, who directs the flow of knowledge among organizations and stimulates innovation.

Originality/value - The choice of the topic is justified by the lack of studies on the identification and analyses of the main aspects of this type of collaboration in an integrated way.
\end{abstract}

Keywords Knowledge management, University-industry-government collaboration, Triple helix

Paper type Research paper

\section{Introduction}

The increasing relevance of information and knowledge for economic and social development and for strengthening competitiveness of organizations has made the diffusion of knowledge and the search for innovation primordial to public and private institutions, resulting in competitive advantage and strategic positioning.

In the knowledge-based economy, the overall performance of innovation depends not only on the performance of specific formal institutions, but rather on how they interact with one another as dimensions of a collective system of knowledge creation and utilization (Beesley, 2003).

In this context, collaboration between universities, industry and government is considered fundamental for knowledge transfer, organizational growth, innovation and economic and social development (Cunningham and Link, 2015; Weckowska, 2015; Schofield, 2013; Morlacchi and Martin, 2009; Salter and Martin, 2001).

(C) Suzana Xavier Ribeiro and Marcelo Seido Nagano. Published in Revista de Gestão. Published by Emerald Publishing Limited. This article is published under the Creative Commons Attribution (CC BY 4.0) licence. Anyone may reproduce, distribute, translate and create derivative works of this article (for both commercial and non-commercial purposes), subject to full attribution to the original publication and authors. The full terms of this licence may be seen at http://creativecommons.org/licences/by/4.0/legalcode 
Nevertheless, in developing countries there is often a low level of research and development $(\mathrm{R} \& \mathrm{D})$ in companies, and related activities are carried out more through the public sector, state-owned companies, research institutes and universities (Sutz, 2000). On the other hand, in the university environment, there is a lack of synergy between teaching missions, research and extension activities, with a fragmentation of functions, which includes university-industry-government cooperation (Liefner and Schiller, 2008). In addition, the collaborative culture is not often embedded in the traditional role of the researcher in the academic context, focusing more on the production and communication of research results.

Although this type of interaction has increased since the 1990s, the main focus is still not the shaping of integrated action policies, but the search for financial benefits (Arza, 2010) or scientists inherent to the area and the segment.

Studies that discuss topics related to knowledge management and university-industrygovernment collaboration are still relatively fragmented (Ankrah and Al-Tabbaa, 2015; Perkmann et al., 2013) and focus especially on the main barriers and motivations for university and industry collaboration (Bruneel et al., 2010). There is a lack of papers dealing with interorganizational collaboration in an integrated way, including the role of government (Ankrah and Al-Tabbaa, 2015), analyzing how effective cooperation can benefit the achievement of individual organizational goals, as well as those of the whole society.

Thus, the objective of this paper is to analyze how certain dimensions of university-industry-government collaboration contribute to knowledge creation, management and transfer, focusing on Brazilian particularities.

In addition to this introduction, this paper has four more sections. The second section presents a literature review on knowledge management, university-industry-government collaboration and the dimensions that influence the two areas: structural, relational, cognitive and context. The third section provides a description of the method used, the fourth presents the case studies with a descriptive synthesis and the conclusions are drawn in the final considerations.

\section{Literature review}

In this topic, a literature review on the main topics addressed in this work is presented: knowledge management and university-industry-government collaboration. It also addresses the most relevant dimensions that influence these two topics concomitantly.

\subsection{Knowledge management and university-industry-government collaboration}

Despite the recognized importance of knowledge as a vital resource for organizational performance, there is little understanding of how organizations actually create and manage knowledge dynamically. In a competitive environment in which the only certainty is uncertainty, the ability to create and use knowledge is the most important source of sustainable competitive advantage for companies, which are seen as a dynamic, evolved and almost autonomous system of knowledge production and application (Nonaka and Takeuchi, 1995; Nonaka et al., 2000; Alavi and Leidner, 2001).

There are two types of knowledge: tacit knowledge and explicit knowledge. Tacit knowledge, which is the cognitive dimension, technical ability, know-how, experience, mental models, beliefs and values, is intrinsic to people, and is hard to be communicated and formalized in concrete ways. Due to the fact that it is formal and systematic, explicit knowledge, on the other hand, is easily processed, shared and stored in documents, manuals, database and other media.

Knowledge conversion (the SECI model) occurs from tacit knowledge (socialization), from tacit to explicit (externalization), from explicit to tacit (internalization) and from explicit to explicit (combination) (Nonaka, 1994; Nonaka et al., 2000). This model can be understood as 
REGE 25,3

the ability of an organization to create knowledge, to disseminate it in all areas and to incorporate it into goods, services and systems (Johannessen et al., 1999). It represents a dynamic process in which the organization creates, maintains and exploits knowledge (Nonaka et al., 2000).

In addition to the SECI model, to understand how organizations create knowledge dynamically, there are two other relevant elements: $b a$, a word of Japanese origin that represents the dynamic and shared organizational context in knowledge creation, dissemination and utilization processes and knowledge resources, which are inputs, outputs and moderate factors of the knowledge creation process (Nonaka and Konno, 1998; Nonaka and Toyama, 2003; Nonaka et al., 2000).

Characterized by the dynamic interactions between members of an organization and between these members and the environment in which they are inserted, the knowledge creation process improves the interaction between individuals, organizations and society, in that it expands the conversion of tacit knowledge to explicit. In an organizational environment, it is important to transform individual learning into collective and continuously create new knowledge (Nonaka, 1994; Nonaka et al., 2000), which is fundamental to boost knowledge transfer and university-industry-government collaboration.

The Triple Helix model, proposed by Etzkowitz and Leydesdorff (2000), is one of the main ones in the field of university-industry-government collaboration and addresses the interrelationships between these three spheres considered fundamental for creating an environment conducive to innovating, generating and disseminating knowledge needed to develop society.

This concept has recently brought about an attempt to better recognize the dynamics of the knowledge-based economy and presents itself as a new knowledge infrastructure generated in terms of overlapping institutional spheres with hybrid organizations emerging from these interfaces (Beesley, 2003).

Interaction between the functions of these three helices takes place by creating communication and knowledge diffusion networks, as well as an environment that stimulates innovation and, consequently, economic and social development (Etzkowitz, 2003; Leydesdorff and Meyer, 2006; Etzkowitz and Leydesdorff, 2000).

In this context, universities maintain their fundamental mission of disseminating knowledge, even if they take on some roles from the industry and government area; industry continues to produce goods and services and also does research, providing high level training and now having expertise in its field; and the government continues as a final guarantor of social functions, besides making it possible to set up new companies (Etzkowitz, 2003).

Thus, the Triple Helix postulates that the (interorganizational) interaction between university, industry and government is the key to improving the conditions for innovation in the knowledge society, insofar as collaboration generates knowledge (Ankrah and Al-Tabbaa, 2015).

\subsection{Dimensions that impact knowledge management and university-industry-government collaboration}

When relating the knowledge management theories and the Triple Helix model, which is characteristic of university-industry-government cooperation, four dimensions considered fundamental were defined: the structural dimension, the relational dimension, the cognitive dimension and the context in which the organizations are inserted.

Structural dimension. According to Nonaka and Toyama (2003), structure influences people. In the conventional theory of organizations, it is believed that the environment has an impact on the structure of the organization, which, in turn, determines people's actions who are part of it. In fact, the structure of the organization does not always directly 
determine people's actions within the organization. On the contrary, the environment and structure are activated and updated by the people in the company while at the same time affecting them (Nonaka et al., 2008).

Among the functions of organizational structure, Hall (2002) highlights the production of organizational results and goals and the determination of how power is exercised (because it fixes or defines hierarchical positions) and how decisions are made (since the flow of information is largely determined by the structure). Thus, the organizational structure is related to the multifunctional integration mechanisms and structuring work teams (Nagano et al., 2014).

Hall (2002) also highlights the characteristics of structure, formalization and centralization. The first refers to factors such as centralization of power and affects a person's behavior as it can empower the individual or even be coercive. It can vary from maximum formalization (assembly line), minimal formalization (individuals need to use their own judgment to decide what to do) or vary in an intermediate position, as in most cases. In turn, centralization is related to the distribution of power in organizations, and is therefore a good way to synthesize the general concept of structure.

In addition to formalization and centralization, Chen and Huang (2007) add the integration between organizational structure elements in knowledge management as one of the factors that affect social interaction. For the authors, the less centralized (more autonomous), the less formalized and the more integrated the organizational structure is, the greater the interaction between the members and the possibility of knowledge management being improved, resulting in knowledge sharing and application.

Organizational control can also be mentioned as one of the factors of structural dimension. According to Magnier-Watanabe et al. (2011), it influences knowledge creation, because an effective definition of organizational objectives, both at the individual and corporate level, guides knowledge to be created and shared to achieve organizational objectives. In addition, they emphasize the following as being relevant: autonomy, because it enables employees to freely seek new methods and knowledge, and creative chaos, a prerequisite for knowledge by stimulating new knowledge creation and innovation.

Relational dimension. The relational dimension analyzes the nature of people and how the relationship between the organizational actors takes place. According to Nonaka et al. (2008, p. 30), to understand "knowledge we must first understand human beings and the interactive processes from which knowledge emerges." Among its main indicators organizational culture, trust and leadership can be highlighted.

Organizational culture can be understood as the pattern of basic premises developed by a given group, how it learns to deal with its problems of external adaptation and internal integration, and how it shares and teaches procedures to new members (Schein, 1985).

In addition, individual and organizational culture are considered as one of the key factors affecting university and industry collaboration (Dell'Ano and Del Giudice, 2015, Ankrah and Al-Tabbaa, 2015). Regarding the nature of people and their interactions, they may assume more cooperative or opportunistic positions, considering that greater collaboration leads to less control. Collectivist cultures are characterized by strong ties between individuals who define them by belonging to a social group, such as the organization they work in, and show high levels of informal communication and interaction (Dell'Ano and Del Giudice, 2015).

Trust also represents an essential aspect of relationships and critically influences outcomes in the interpersonal, intra-organizational and interorganizational collaboration dimensions. Values and norms within the social structure significantly influence interpersonal dynamics insofar as they produce mutual support and confidence building, facilitating cooperation and coordinating collective actions (Putman, 1993; Kianto and Waajakoski, 2010).

\section{University- business- government collaboration}


REGE 25,3
Bruneel et al. (2010) argue that interorganizational trust, as well as the experience of collaboration and the breadth of interaction channels are considered as potential mechanisms to minimize obstacles to university-industry collaboration related to differences in company and university orientation and conflicts of intellectual property.

In addition, the way of coordinating and leadership needs to be adapted to the characteristics of each institution, since different organizations require different forms of coordination and leadership (Nooteboom, 2000). Those in charge of organizations can manage the action directly (decision-making level); manage people to encourage them to take the necessary actions (interpersonal level) and manage information to influence people to take action (informational level) (Mintzberg and Quinn, 1998).

Two other types of leadership are conceptualized by Magnier-Watanabe et al. (2011): achievement-oriented leadership, with a greater focus on organizational goals, and people-oriented leadership, which includes team dynamics and can consequently encourage knowledge sharing among members.

Cognitive dimension. The cognitive dimension refers to shared codes and narratives and a common understanding of organizational goals (Al-Tabbaa and Ankrah, 2016), and can therefore be characterized according to the communicative processes and the nature of the transferred knowledge.

Communication flows can occur through the media: traditional, such as oral, suitable for face-to-face communication (such as e-mails, social media, teleconferencing equipment, video and voice calls over the internet, etc.) and the use of the internet, instant messaging over smartphones, among others.

Communication flows can occur through means of communication: traditional, such as oral, suitable for face-to-face communication; written (such as books, newspapers, magazines, manuals, leaflets, banners, reports, among others), audiovisual and modern digital media (such as e-mails, social media, teleconferencing equipment, video and voice calls over the internet, instant messaging by smartphones, among others).

In addition, knowledge propagates within a "contextualized space," known as $b a$, which can be classified as: formal $b a$ refers to opportunities formally provided by the organization such as scheduled meetings and institutionalized forums to interact with others; informal $b a$ is related to opportunities for casual communication and not defined by the organization or work process; and cyber $b a$ which are interactions by electronic media (Magnier-Watanabe et al., 2011).

Among the factors that impair knowledge transfer are the characteristics of transferred knowledge, the source/sender, the receiver and the context in which the transfer happens (Szulanski, 1996).

From a relational perspective, the role of communication in facilitating organizational learning is not limited to enabling the flow of communication. In addition, it is responsible for mediating the process of participation in teamwork practices, guiding the development of a common language and sharing identity and knowledge (Michailova and Sidorova, 2011).

Executing a communication plan properly is critical for implementing knowledge management in an organization. As it is the people who make things happen and who are responsible for implementing and seeing through changes in the organizational environment, it is important that the appropriate message is transmitted through a communication vehicle appropriate for the right people (Mei et al., 2004).

Collaboration is based on communicating information that, in the era of new information and communication technologies (ICTs), increasingly occurs through multilevel networks, from local to international (Etzkowitz, 2008). Those who have too much knowledge to improve their internal capacity or whose mission is exchanging knowledge (universities and training systems in general) provide knowledge to those in need and who have the ability to 
acquire and improve it (Davenport and Prusak, 1998), as in the cases of companies, that is, knowledge exchange occurs in two directions: from universities to industry and vice versa.

Figure 1 shows a schematic diagram of the dimensions that influence the knowledge management and university-industry-government collaboration.

\section{Research method}

This study is of an applied and descriptive nature adopting a qualitative approach and includes case studies in order to understand the dimensions that have an impact on knowledge creation and management in university-industry-government collaboration in the Brazilian context.

A case study is a qualitative form of research that analyzes the phenomenon in its real environment, based on multiple sources of evidence. It is recommended when the social and personal context is fundamental in understanding and interpreting the phenomenon (Neuman, 2010; Yin, 2013). This paper is based on a double case study concerning representatives from the National Institutes of Science and Technology (INCTs) program that have stood out in terms of their contribution to scientific advancement, knowledge transfer and scientific dissemination to society.

Empirical evidence is based on documents or materials, such as information on Institutes' websites and in reports (secondary sources) and semi-structured interviews (primary sources). The interviews were based on a pre-defined open-ended questionnaire, formulated according to the main general foundations of knowledge management and Triple Helix theories and the proposed dimensions in order to conduct interviews to ensure that all the concepts raised were investigated. Two coordinators were interviewed, one from each Institute (A and $\mathrm{B}$ ), and one from the representatives of the managing committee of Institute A.

To analyze the collected data, we used the categorial content analysis that examines the text in its entirety in order to carry out a classification using the method of significant categories of the message. The technique classifies the various elements into categories which are criteria capable of giving rise to a sense capable of introducing a certain order into the initial confusion. It is evident that everything depends, when choosing the classification criteria, on what one seeks or expects to find (Bardin, 1977). In addition, the analysis should

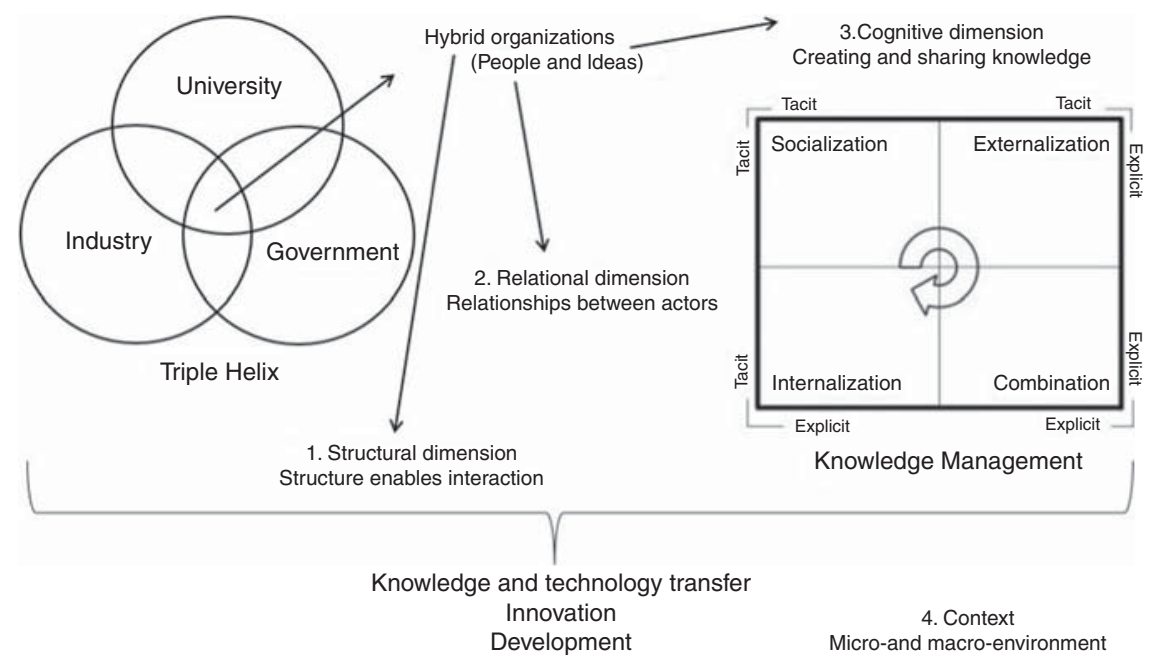

Universitybusinessgovernment collaboration
Figure 1. Dimensions that influence knowledge management and the university-industrygovernment collaboration 
REGE 25,3 not be limited to what is explicit in the material, but seek to unveil implied messages, contradictory dimensions and systematically silenced themes (Lüdke and André, 1986).

The interviews lasted an average of forty (40) minutes each. Their audio was transcribed in text format and analyzed according to the following steps of categorical discourse analysis, proposed by Bardin (1977): floating reading, choice of categories, organization in indicators, cuts of themes that are repeated and categorization. This last phase joins the main information collected relating it or not to the proposed theoretical references. As each hour of recorded interview corresponds to at least $4 \mathrm{~h}$ of transcription, there were approximately 12 hof analysis in total.

The following topic provides a description of the case studies and the comparative analysis of the data.

\section{Case study}

This paper focuses on institutes representing the INCT Program, launched in 2008 with the aim of promoting innovation through scientific and technological development in Brazil with a focus on the real needs of society. Initially, in 2009, 120 institutes were created and, in November 2016, the Coordinating Committee of the INCTs announced the definition of 101 projects (new or continuity of previous ones) to receive resources under the 2014 call. The program is an initiative from the Ministry of Science, Technology and Innovation (MCTI in Portuguese), through the National Council for Scientific and Technological Development (CNPq in Portuguese), in partnership with the Coordination for the Improvement of Higher Education Personnel (CAPES in Portuguese), the São Paulo Research Foundation (FAPESP in Portuguese) and other state research support foundations (FAPs in Portuguese).

The INCT is one of the largest Science and Technology programs in the country and seeks to mobilize and aggregate, in an articulated way, the best research groups in frontier areas of science and in strategic areas for the country's sustainable development; to promote basic and fundamentally competitive international scientific research; stimulate the development of advanced scientific and technological research associated with applications to promote innovation and entrepreneurship, in close coordination with innovative companies, in the areas of the Brazilian System of Technology (Sibratec).

The program is segmented according to the area of activity: Agrarian; Energy; Exact and Natural Sciences; Engineering and Information Technology; Nanotechnology; Ecology and Environment; Health and Human and Social. In this paper, the case studies are based on two institutes: one in the area of Engineering and Information Technology and another in Exact and Natural Sciences.

These two institutes were selected because they are outstanding cases within the INCT program due to the important results achieved by interaction between researchers in their fields throughout Brazil and by the effective collaboration with companies. Institute A was one of the pioneers in research and production of unmanned aerial and ground vehicles in the country and Institute B contributes significantly to advances in the area of health, among them aimed at cancer treatments.

In a CNPq publication on the results and impacts of the INCT program (CNPq, 2016), Institutes $\mathrm{A}$ and $\mathrm{B}$ are cited among the 21 mentioned quantitative examples highlighted, selected among the 125 underway at the time. In the case of Institute A, it is emphasized that "an unmanned aerial vehicle [...] has been developed that has been in the spotlight in the media and is already being marketed by a Brazilian partner company." Concerning Institute $\mathrm{B}$, it is stated that "several spin-off companies already produce and commercialize new protocols and equipment for using photodynamic therapy to treat various types of cancer, as well as new techniques for evaluating organs for transplants."

As this study focuses on the university-industry-government collaboration, represented by the INCT program in the Brazilian context and there are organizations that integrate 
these institutes in all the states of the country, the external context in which they are inserted is important, as it can have an impact on knowledge creation and management processes regarding the integration of these organizations. Therefore, the context is also considered in this paper as a variable when analyzing these processes.

Organizations and their external environment influence each other concomitantly. This environment can be considered both macro and micro. The macro-environment refers to elements that affect the organization indirectly, such as social, political, demographic, ecological, cultural, economic, legal, technological and cultural, among others factors. In turn, the micro-environment is closer and incorporates sectors or organizations that are part of the organization's daily life, directly influencing its basic activities and performance.

When considering the Brazilian context (macro-environment), Santos and Torkomian (2013) emphasize that the legal framework to promote innovation includes agreements between universities and industry in partnerships frequently financed and stimulated by governmental resources.

Among the frameworks to foster technological innovation in Brazil and realign universities in the knowledge economy (Santos and Torkomian, 2013), the adoption of the Innovation Law in 2004 is highlighted. According to this law, innovation as a means of transforming knowledge into wealth and improving the quality of life of the population is organized into three axes: creating an environment conducive to strategic partnerships between universities, technological institutes and companies; encouraging science and technology institutes to participate in the innovation process; and stimulating innovation in the industry.

In addition, the new Legal Framework for Science, Technology and Innovation, approved in January, 2016, promotes a series of actions to encourage research, innovation and scientific and technological development in Brazil, enabling public sectors producing knowledge, such as universities and research institutes and the industry to interact closely.

\subsection{Descriptive summary of the collaboration in national institutes of science and technology}

Institute $A$. The first of them (Institute A) in the area of Engineering and Information Technology began in 2009 and, after 2014, its members regrouped in other collaboration networks, including a new INCT, which had another name. The headquarters are located in São Carlos, São Paulo state. Moreover, it has contributed significantly to developing the area of critical embedded systems in Brazil, especially pioneering the development of unmanned aerial vehicles (UAVs and drones) and terrestrial autonomous vehicles. Comprising about 350 members, six companies and 21 laboratories, integrating 12 Brazilian university and research institutions from the north to south of the country, it has established partnerships with security and environmental sectors.

Among the main results obtained by Institute A, it is highlighted in a report sent to the development agencies, that "a totally national, low cost, electric vehicle was developed. This development has acquired enough knowledge so that not only the development of unmanned aircraft could be possible, but this technology can also be increasingly seen today to be developing and used in various application domains. The development of architectures, models, more advanced security, control and navigation techniques could be explored."

"Similarly, a stand-alone ground vehicle has been developed [...]. Navigation systems based on computer vision, new algorithms and techniques have been and are being developed allowing the area to develop. Stereo cameras, among others, have been used in important fields of application. Sensor fusion has allowed significant advances in the area, such as the fact that CARINA II is the first autonomous car to run in an urban environment in Latin America." 
REGE 25,3
Commenting on the INCT program's relationship with knowledge management and university-industry-government collaboration, the Institute's coordinator stated that "this is really the type of project that needs to be developed more and more in Brazil by exploring knowledge generation and utilization in a more dynamic way. This is critical for actually having a greater transfer of technology, facilitating innovation and entrepreneurship developing into ongoing training of human resources for various strategic areas."

The coordinator adds that the program is important "because it uses resources, motivates people, brings results that the individual sum of actions would not bring." To improve this kind of collaboration in the country, it is important to think in terms of an industrial park with good incentives. In addition, "industry that fosters innovation, entrepreneurship and development knows that it depends on scientific advancement. Innovation and entrepreneurship are strongly related to post-graduate programs with a strong human resource background."

Structural dimension. The institute had a hierarchical structure established with the coordinator, vice-coordinator, directors, centers, working groups and researchers who had defined functions. Organizational objectives were followed, and the so-called deliverables (land and air autonomous vehicles) were developed. Openness to new ideas was a reality that was observed, including creating new research groups and agreements while the INCT was underway.

Relational dimension. Concerning the establishment of an organizational culture and innovation, the coordinator stated that the "project of the Institute was born from this culture" and previous contacts were the basis of the collaboration. The coordinator believes that there was trust among the members and that the leadership involved both directly working on the projects, encouraging people to search for initiatives or exchange information, according to each situation experienced.

Cognitive dimension. Knowledge was made available to society, mainly by publishing articles, deliverables, holding events and scientific dissemination. "Certainly when you have results of social and economic impact this should also be brought to the knowledge of society in a more popularized way so that it itself recognizes the value of investment and supports, as well as requesting investments, because without science, society does not evolve." Internally, various ICT tools (such as e-mails and photo and video calls over the internet), more formal mechanisms (such as articles and reports) were used, as well as local and global evaluation workshops about the project.

Among the possible communicative or intrinsic barriers to this kind of collaboration are those related to cultural differences and perspectives of university and industry achievements, and to the need to improve communication in collaboration networks with a view to scientific diffusion. "From the point of view of science and technology production, the great barrier is the lack of a model that involves copyright, intellectual property and agreements," integrating the everyone's point of view involved.

Context. In addition, the coordinator believes that the context has an impact on knowledge creation and university-industry-government cooperation, since in the case of its area of activity there are still important companies in the area, as in other countries, so there are international models of this kind of collaboration that works better than in Brazil.

Geographical proximity. Considering the continental dimensions of our country, it should be observed that this type of proximity facilitates the cooperation. The coordinator cites examples of university environments that already have industries, research centers, integrated innovation agencies, but highlights the importance of knowing how to collaborate regardless of geographic proximity.

Institute B. The other institute (Institute B) is in the area of Exact and Natural Sciences, more specifically Optics and Photonics, and the main objectives of the first phase 
(from 2009 to 2016) were to develop fundamental and applied multidisciplinary research, integrating specialists from different areas (physics, chemistry, medical sciences and engineering) to explore new applications, highlighting those focusing on health, disseminate the area to the general public, taking science to all levels of education, and promoting innovation in industry through technology transfer, small business incubation, continuing education and training programs.

Considering a partnership with 11 companies, working on development projects, mainly mid-term duration, they also have the vocation to create new companies - startups and spin-offs. The institute, based in São Carlos, São Paulo state generates on average 70 jobs and trains about 30 post-graduate students per year, and this new phase of INCT is more focused on innovation. The coordinator said "I have found that we are good at collaborating with and helping companies, but this is not enough today. Some technologies that are disruptive, that will change the state of the art, they start with new companies and that is why I want to try to add this aspect to our research center, through this National institute project."

In a report sent to the development agencies, it is highlighted that "a total of more than $\mathrm{R} \$ 1,500.00$ per year is obtained for direct collaboration programs with companies for both exploratory projects with companies and for developing new instrumentation or new methodologies."

The concern about knowledge management is already highlighted in the proposal of Institute B. "There is great knowledge production, but sometimes there is a difficulty in finding mechanisms that translate this into technological innovation. Today, you have to have this connection of knowledge management, technological innovation and entrepreneurship to produce a model that allows you to evaluate how certain technologies should start, it is not just a matter of starting."

Structural dimension. Concerning the critical factors, the following evidence was found: it has an established hierarchical structure with the coordinator, vice-coordinator and coordinators by area, with pre-established functions from the project design. The members follow the organizational objectives and have the autonomy to propose new ideas. "It is not a set of disconnected pieces, so you do not need a National Institute."

Relational dimension. The importance of having a general philosophy, an ideological affinity, that is, a culture and organizational trust is highlighted. They also present the so-called innovation culture. Regarding leadership, the coordinator believes that "the coordinator has to be a link with all parties from undergraduate students to partner companies."

Cognitive dimension. Scientific knowledge is accumulated and recorded in the form of articles, patents and seminars. Internally, there is an organization chart established with the objective of making known what is being developed in each subproject clearly and there are regular meetings for self-assessment, which is part of the coordinator's management philosophy, stating that "meetings are good to decide what to do, but someone has to take responsibility."

The coordinator does not believe that there are barriers, but rather "non-established procedures." He stresses that there is a difficulty related to the interface between the university and productive sector because of differences in thinking, time scales and developmental obligations (advancing knowledge $\times$ billing), "but that is why we have an institute, exactly to create these types of models" with the learning acquired over time. He emphasizes that it is important for universities to play the role of governance in this type of model.

Context. The coordinator believes that the context influences innovation and university-industry-government collaboration. And that "the government has to start
Universitybusinessgovernment collaboration 
REGE

25,3

268

stimulating an innovation that meets certain needs, as well as attend the economic reality." The government should not only create an initiative to encourage collaboration but also be part of the absorption of knowledge and products generated, and serve as a good example of complying with laws and strengthening industry.

Geographical proximity. The coordinator does not consider it important to facilitate this collaboration and emphasizes that the very creation of the INCT Program is intended to promote this integration.

Table I presents a synthesis of how the dimensions proposed by the work were identified in each of the institutes studied.

\subsection{Comparative data analysis}

Considering the information collected during the interviews, it is observed that the interviewees' opinions, as well as the characteristics of the dimensions studied, coincide in some aspects.

In the institutes studied, it can be observed that there is a formalization defined with different hierarchical levels that make them less centralized and dependent on the figure of the coordinator, although the coordinator is very active and facilitates the integration and flow of knowledge. The importance of the figure of the coordinator and his/her leadership is also fundamental in monitoring the progress of actions related to the goals established in the projects, as well as motivating the other members toward them.

The function of leadership is to facilitate the knowledge creation process. Governance mechanisms, which can pressure opportunism and increase trust at an interorganizational level, as well as social control, the system of aligning interests and forms of negotiation, are dependent on the structure and architecture of the network (Nonaka et al., 2008; Ahuja et al., 2012; Sacomano Neto and Truzzi, 2004).

It can be observed by analyzing the trust and culture of innovation among the members of these representatives of the INCT program that these institutes, representatives of university-industry-government cooperation, create a differentiated virtual $b a$ that facilitates both the sharing of tacit and explicit knowledge, i.e., the so-called cognitive distance.

The knowledge developed by the institutes comes to society mainly through publishing scientific articles, patents, deliverables and giving seminars, as well as scientific dissemination, a highly valued area which has obtained significant results in both institutes and have counted on researchers dedicated to this function.

It can be observed that knowledge management is considered important by the two coordinators who seek to stimulate the knowledge transfer and technologies produced both for the productive sector through partnerships with companies and stimulating setting up new companies, also collaborating with the government to establish public policies, and for the society as a whole, since both institutes develop important research in the area of scientific dissemination. The two institutes also have researchers who are specifically responsible for diffusion and scientific dissemination.

Regarding possible barriers, the coordinators highlight those related to cultural differences and the objectives of the university and industry, which differ in thinking, time scales and the development of obligations.

Regarding the importance of geographic proximity to university and industry collaboration, the two coordinators expressed slightly different views on the subject. Considering the continental dimensions of our country, for the coordinator of Institute A, this type of proximity facilitates the collaboration. He cites examples of university environments that already have industries, research centers, integrated innovation agencies, but highlights the importance of knowing how to collaborate regardless of geographic proximity. The coordinator of Institute B does not consider it important and emphasizes 


\begin{tabular}{|c|c|c|c|c|c|}
\hline $\begin{array}{l}\text { Dimension } \\
\text { Internal level }\end{array}$ & Indicators & Characteristics & Institute A & Institute B & business- \\
\hline \multirow[t]{3}{*}{ Structural } & $\begin{array}{l}\text { Organizational } \\
\text { control }\end{array}$ & $\begin{array}{l}\text { Clear individual and } \\
\text { organizational goals, } \\
\text { autonomy and } \\
\text { creative chaos }\end{array}$ & $\begin{array}{l}\text { Members engaged in } \\
\text { organizational goals } \\
\text { and proposed new ideas } \\
\text { and partnerships } \\
\text { with companies }\end{array}$ & $\begin{array}{l}\text { Members need to follow } \\
\text { organizational goals. } \\
\text { There are self- } \\
\text { assessment meetings } \\
\text { and autonomy to }\end{array}$ & $\begin{array}{r}\text { government } \\
\text { collaboration } \\
\mathbf{2 6 9}\end{array}$ \\
\hline & Formalization & $\begin{array}{l}\text { Maximum, intermediate } \\
\text { or minimum }\end{array}$ & $\begin{array}{l}\text { Members had well- } \\
\text { defined roles both in the } \\
\text { administrative and } \\
\text { thematic areas }\end{array}$ & $\begin{array}{l}\text { propose new ideas } \\
\text { Functions and roles } \\
\text { pre-established in the } \\
\text { project }\end{array}$ & \\
\hline & Centralization & High, medium, low & $\begin{array}{l}\text { Hierarchical structure } \\
\text { defined with } \\
\text { coordinator, vice- } \\
\text { coordinator, directories, } \\
\text { centers, working groups } \\
\text { and researchers }\end{array}$ & $\begin{array}{l}\text { Hierarchical structure } \\
\text { defined with coordinator } \\
\text { (very active), } \\
\text { vice- coordinator and } \\
\text { coordinators by area }\end{array}$ & \\
\hline \multirow[t]{3}{*}{ Relational } & $\begin{array}{l}\text { Culture } \\
\text { (organizational } \\
\text { and innovation) }\end{array}$ & $\begin{array}{l}\text { Identify if culture of } \\
\text { collaboration and } \\
\text { innovation exist }\end{array}$ & $\begin{array}{l}\text { Institute was born as a } \\
\text { result of the culture of } \\
\text { innovation and } \\
\text { collaboration already } \\
\text { existing between } \\
\text { members before its } \\
\text { foundation and } \\
\text { expanded with it }\end{array}$ & $\begin{array}{l}\text { "Team cohesive around } \\
\text { established goals." } \\
\text { Culture of innovation } \\
\text { is present }\end{array}$ & \\
\hline & Trust & $\begin{array}{l}\text { Interpessoal, } \\
\text { intra-organizacional, } \\
\text { e interorganizacional }\end{array}$ & Believes to be present & $\begin{array}{l}\text { Present, best way to be } \\
\text { generated is "do not } \\
\text { give chance to } \\
\text { generate distrust" }\end{array}$ & \\
\hline & Leadership & $\begin{array}{l}\text { People-oriented, goal- } \\
\text { oriented, informational, } \\
\text { interpersonal, } \\
\text { decisional, transactional } \\
\text { or transformational }\end{array}$ & $\begin{array}{l}\text { Covers a little of each } \\
\text { orientation; coordinator } \\
\text { needs to be aware of the } \\
\text { administrative part and } \\
\text { the look of a scientist }\end{array}$ & $\begin{array}{l}\text { Coordinator needs to be a } \\
\text { link with all the integral } \\
\text { parts of the project and } \\
\text { have full knowledge of } \\
\text { the activities }\end{array}$ & \\
\hline \multirow[t]{4}{*}{ Cognitive } & $\begin{array}{l}\text { Nature of } \\
\text { knowledge } \\
\text { transferred }\end{array}$ & Tacit and explicit & $\begin{array}{l}\text { Among members: ICTs } \\
\text { e-mail, voice and video } \\
\text { call service over the } \\
\text { internet. In addition to } \\
\text { local and global project } \\
\text { evaluation workshops. } \\
\text { For society: articles, } \\
\text { scientific dissemination } \\
\text { and deliverables }\end{array}$ & $\begin{array}{l}\text { Among members: } \\
\text { knowledge flows well } \\
\text { by organization chart } \\
\text { proposed to make } \\
\text { known each project in a } \\
\text { clear way } \\
\text { For a society: articles, } \\
\text { patents, seminars and } \\
\text { scientific dissemination }\end{array}$ & \\
\hline & Types of $b a$ & Formal, informal e cyber & Three coexist & Three coexist & \\
\hline & $\begin{array}{l}\text { Main channels } \\
\text { and flows }\end{array}$ & $\begin{array}{l}\text { Face to face, oral, } \\
\text { printed, digital }\end{array}$ & Digital and face to face & Digital and face to face & \\
\hline & $\begin{array}{l}\text { Possible } \\
\text { communicative } \\
\text { barriers and/or } \\
\text { to u-b-g } \\
\text { collaboration }\end{array}$ & $\begin{array}{l}\text { References: transferred } \\
\text { knowledge, source/ } \\
\text { sender, receiver, } \\
\text { information asymmetry }\end{array}$ & $\begin{array}{l}\text { Related to cultural } \\
\text { problems regarding } \\
\text { scientific dissemination } \\
\text { in collaboration } \\
\text { networks and to } \\
\text { different perspectives } \\
\text { between university } \\
\text { and industry }\end{array}$ & $\begin{array}{l}\text { Present at the } \\
\text { university and industry } \\
\text { interface for differences } \\
\text { in way of thinking, } \\
\text { time scales and } \\
\text { developmental } \\
\text { obligations }\end{array}$ & $\begin{array}{r}\text { Table I. } \\
\text { Dimensions of } \\
\text { university-business- } \\
\text { government } \\
\text { collaboration in } \\
\text { the institutes }\end{array}$ \\
\hline
\end{tabular}


REGE 25,3

270

Table I.

\section{Dimension Indicators $\quad$ Characteristics $\quad$ Institute A Institute B \\ Internal level}

External level

Context Macro-

environment

Micro-

environment

Geographical

proximity

between

academic and

business

environment
Influences collaboration and stimulates

innovation

Facilitates collaboration and innovation
There is influence of the There is influence both world context, national in the area of action and and the area of in the national context performance

Believes that it facilitates collaboration
There is not influence on collaboration

that the very creation of the INCT Program is intended to promote this integration. There is a consensus regarding the influence of the context concerning the area of performance and the country.

\section{Final considerations}

The comparative results presented show the importance of creating the INCTs for Brazilian scientific and technological development by giving rise to institutes with their own structures and coordination that integrate the most renowned researchers of important fields in the country, as well as fostering integration with companies and, thus, transferring technology, innovation and development in our country.

These characteristics refer to the structural dimension, identified in the present study, which is consistent with the guidelines on INCTs from CNPq and MCTI, which argues that each National Institute should have "a clearly defined theme or area of activity [...], backed by a well-structured scientific or technological research program [...], consisting of a headquarters and a network of research groups organized regionally or nationally $[\ldots]$ and have physical space and infrastructure that enable a visible characterization."

It can be observed that participation in these INCTs allowed the creation of an organizational structure, centered on the figure and leadership of the coordinator, that enables and directs the flow of knowledge among the member organizations, but also stimulates the proposition of new ideas. The leadership of the coordinator and his management committee (relational dimension) are relevant to create trust among the members of the institutes, companies and government representatives, thus fostering the creation of a collaborative and innovative culture, with room for proposing new ideas and valuing knowledge management, which facilitates knowledge and technology transfer and, consequently, national development.

To reduce possible barriers in university-industry-government collaboration arising from different characteristics and objectives, according to the coordinator of Institute B, certain procedures should be adapted considering what was learnt while collaborating and what can be better worked on with effective knowledge management. That is, knowledge exchange (cognitive dimension) between representatives of the three spheres of the Triple Helix, university, industry and government, is the result of constant learning, which can be facilitated by being part of the structure and relationships created by integrating a program such as INCT. 
In addition, inherent characteristics to the context, both regarding the micro-environment and the macro-environment, can have an impact on this cooperation. The government contributes significantly to the financial support given to the INCT program, but could develop measures that will help implement innovations, encouraging and facilitating, for example, setting up and maintaining companies. The coordinator of Institute B says that the government, besides "being a supporter, needs to be an example to be followed. Not only to finance institutes like these, but also participate in absorbing what is produced." Stimulating and collaborating with strengthening industrial parks in Brazil is fundamental for reinforcing the academic-industry relationship, as emphasized by both coordinators of the institutes.

Inherent characteristics of the INCTs studied, such as those highlighted above, facilitate university-industry-government collaboration and scientific and technological development, but there are still many challenges to be overcome.

Every university in the world, as well as public and private research centers, interacts differently with industry. Cultural and economic differences make it difficult to outline a single model to guide knowledge and technology transfer (Dell'Ano and Del Giudice, 2015). Nevertheless, it is important to think of a more coherent model or tools, as in our context, which can contribute to this type of collaboration. In other words, what can be researched in future studies.

The following limitations of this study can be mentioned: it is unlikely that completing only one case study considers all the elements to identify variables when studying the relationship between the knowledge management and Triple Helix theories (university-industry-government collaboration). However, the results obtained already enable us to outline these elements, making it possible to use them in future studies in other programs or initiatives that encourage the knowledge and technology transfer through this type of collaboration.

\section{References}

Ahuja, G., Soda, G. and Zaheer, A. (2012), "The genesis and dynamics of organizational networks", Organization Science, Vol. 23 No. 2, pp. 434-448.

Alavi, M. and Leidner, D. (2001), "Review: knowledge management and knowledge management systems: conceptual foundations and research issues”, MIS Quartely, Vol. 25 No. 1, pp. 107-136.

Al-Tabbaa, O. and Ankrah, S. (2016), "Social capital to facilitate 'engineered' university-industry collaboration for technology transfer: a dynamic perspective", Technological Forecasting and Social Change, Vol. 104 No. C, pp. 1-15.

Ankrah, S. and Al-Tabbaa, O. (2015), "University-industry collaboration: a systematic review", Scandinavian Journal of Management, Vol. 31 No. 3, pp. 387-408.

Arza, V. (2010), "Channels, benefits and risks of public-private interactions for knowledge transfer: a conceptual framework inspired by Latin America”, Science and Public Policy, Vol. 37 No. 7, pp. 473-484.

Bardin, L. (1977), Análise de Conteúdo, Edições 70, Lisboa, p. 70.

Beesley, L.G.A. (2003), "Science policy in changing times: are governments poised to take full advantage of an institution in transition?”, Research Policy, Vol. 32 No. 8, pp. 1519-1531.

Bruneel, J., D'Este, P. and Salter, A. (2010), "Investigating the factors that diminish the barriers to university-industry collaboration", Research Policy, Vol. 39 No. 7, pp. 858-868.

Chen, C. and Huang, J. (2007), "How organizational climate and structure affect knowledge management - the social interaction perspective", International Journal of Knowledge Management, Vol. 27 No. 2, pp. 104-118.

CNPq (2016), "Resultados e impactos do programa institutos nacionais de Ciência e tecnologia", available at: http://confap.org.br/news/wp-content/uploads/2016/06/panorama-INCT-CONFAPMaranh\%C3\%A3o-1.pdf (accessed April 12, 2018). 
REGE 25,3

Cunningham, J.A. and Link, A.N. (2015), "Fostering university-industry R\&D collaborations in European Union countries", International Entrepreneurship and Management Journal, Vol. 11 No. 4, pp. 849-860.

Davenport, T. and Prusak, L. (1998), Working Knowledge: How Organizations Manage What they Know, Harvard Business School Press, Boston, MA.

Dell'ano, D. and Del Giudice, M. (2015), "Absorptive and adsorptive capacity of actors within university-industry relations: does technology transfer mater?", Journal of Innovation and Entrepreurship, Vol. 4 No. 13, pp. 1-20.

Etzkowitz, H. (2003), "Innovation in innovation: the triple helix of university-industry-government relations", Social Science Information, Vol. 42 No. 3, pp. 293-337.

Etzkowitz, H. (2008), The Triple Helix: University-Industry-Government Innovation in Action, Routledge, New York, NY.

Etzkowitz, H. and Leydesdorff, L. (2000), "The dynamics of innovation: from national systems and 'mode 2' to a triple helix of university-industry-government relations", Research Policy, Vol. 29 No. 2, pp. 109-123.

Hall, R.H. (2002), Organizations: Structures, Processes, and Outcomes, 8th ed., Prentice Hall, Englewood Cliffs, NJ.

Johannessen, J., Olsen, B. and Olaisen, J. (1999), “Aspects of innovation theory based on knowledgemanagement”, International Journal of Information Management, Vol. 19 No. 2, pp. 121-139.

Kianto, A. and Waajakoski, J. (2010), "Linking social capital to organizational growth", Knowledge Management Research \& Practice, Vol. 8 No. 1, pp. 4-14.

Leydesdorff, L. and Meyer, M. (2006), "Triple helix indicators of knowledge-based innovation systems. Introduction to the special issue", Research Policy, Vol. 35 No. 1, pp. 1441-1449.

Liefner, I. and Schiller, D. (2008), "Academic capacities in developing countries-a conceptual framework with empirical illustrations from Thailand", Research Policy, Vol. 37 No. 2, pp. 276-293.

Lüdke, M. and André, M.E.D. (1986), Pesquisa Em Educação: Abordagens Qualitativas, Editora Pedagógica e Universitária, São Paulo.

Magnier-Watanabe, R., Benton, C. and Senoo, D. (2011), "A study of knowledge management enablers across countries”, Knowledge Management Research \& Practice, Vol. 9 No. 1, pp. 17-28.

Mei, Y.M., Lee, S.T. and Al-Hawamdeh, S. (2004), "Formulating a communication strategy for effective knowledge sharing", Journal of Information Science, Vol. 30 No. 1, pp. 12-22.

Michailova, S. and Sidorova, E. (2011), "From group-based work to organizational learning: the role of communication forms and knowledge sharing", Knowledge Management Research \& Practice, Vol. 9 No. 1, pp. 73-83.

Mintzberg, H. and Quinn, J.B. (1998), The Strategy Process: Concepts, Contexts, Cases, Prentice Hall, London.

Morlacchi, P. and Martin, B.R. (2009), "Emerging challenges for science, technology and innovation policy research: a reflexive overview", Research Policy, Vol. 38 No. 4, pp. 571-582.

Nagano, M.S., Stefanovitz, J.P. and Vick, T.E. (2014), "Innovation management processes, their internal organizational elements and contextual factors: an investigation in Brazil", Journal of Engineering and Techonology Management, Vol. 33 Nos 7-9, pp. 63-92.

Neuman, W.L. (2010), Social Research Methods: Qualitative Evaluation and Research Methods, 2nd ed., Sage Publications, London, pp. 277-367.

Nonaka, I. (1994), “A dynamic theory of organizational knowledge creation”, Organization Science, Vol. 5 No. 1, pp. 14-37.

Nonaka, I. and Konno, N. (1998), "The concept of 'Ba': building a foundation for knowledge creation”, California Management Review, Vol. 40 No. 3, pp. 40-55.

Nonaka, I. and Takeuchi, H. (1995), The Knowledge Creating Company: How Japanese Companies Create the Dynamics of Innovation, Oxford University Press, Oxford. 
Nonaka, I. and Toyama, R. (2003), "The knowledge-creating theory revisited: knowledge creation as a synthesizing process", Knowledge Management Research \& Practice, Vol. 1 No. 1, pp. 2-10.

Nonaka, I., Toyama, R. and Hirata, T. (2008), Managing Flow: A Process Theory of the Knowledge-Based Firm, Palgrave Macmillan, New York, NY.

Nonaka, I., Toyama, R. and Konno, N. (2000), "SECI, ba and leadership: a unified model of dynamic knowledge creation", Long Range Planning, Vol. 33 No. 1, pp. 5-34.

Nooteboom, B. (2000), "Institutions and forms of co-ordination in innovation systems", Organization Studies, Vol. 21 No. 5, pp. 915-939.

Perkmann, M., Tartari, V., Mckelsey, M., Autio, E., Broström, A., D’Este, P., Fini, R., Geuna, A., Grimaldi, R., Hughes, A., Krabel, S., Kitson, M., Llerena, P. and Lissoni, F. (2013), "Academic engagement and commercialisation: a review of the literature on university-industry relations", Research Policy, Vol. 42 No. 2, pp. 423-442.

Putman, R. (1993), "The prosperous community: social capital and public life", The American Prospect, Vol. 4 No. 13 , pp. $35-42$.

Sacomano Neto, M. and Truzzi, O.M.S. (2004), "Configurações estruturais e relacionais da rede de fornecedores: uma resenha compreensiva”, Revista Administração, Vol. 39 No. 3, pp. 255-263.

Salter, A.J. and Martin, B.R. (2001), "The economic benefits of publicly funded basic research: a critical review", Research Policy, Vol. 30 No. 3, pp. 509-532.

Santos, M.E.R. and Torkomian, A.L.V. (2013), "Technology transfer and innovation: the role of the Brazilian TTOs", International Journal of Technology Management \& Sustainable Development, Vol. 12 No. 1, pp. 89-111.

Schein, E.H. (1985), Organization Culture and Leadership, Jossey-Bass, San Francisco, CA.

Schofield, T. (2013), "Critical success factors for knowledge transfer collaborations between university and industry", Journal of Research Administration, Vol. 44 No. 2, pp. 38-56.

Sutz, J. (2000), "The university-industry-government relations in Latin America", Research Policy, Vol. 29 No. 2, pp. 279-290.

Szulanski, G. (1996), "Exploring internal stickiness: impediments to the transfer of best practice within the firm”, Strategic Management Journal, Vol. 17 No. 2, pp. 27-43.

Weckowska, D.M. (2015), "Learning in university technology transfer offices: transactions-focused and relations-focused approaches to commercialization of academic research", Technovation, Vols 41-42, pp. 62-74.

Yin, R.K. (2013), Case Study Research: Design and Methods, 5th ed., Sage Publications, Los Angeles.

\section{Further reading}

Johannessen, J. (2008), "Organizational innovation as part of knowledge management", International Journal of Information Management, Vol. 28 No. 5, pp. 403-412.

\section{Corresponding author}

Marcelo Seido Nagano can be contacted at: drnagano@usp.br

For instructions on how to order reprints of this article, please visit our website:

www.emeraldgrouppublishing.com/licensing/reprints.htm

Or contact us for further details: permissions@emeraldinsight.com
Universitybusinessgovernment collaboration 